\title{
Office hysteroscopy prior to ART cycle-analysis and outcome at a private IVF clinic setup in Surat, Gujarat, India
}

\section{Meeta Mohan Mahale*, Purnima Kishore Nadkarni, Kishore Mohan Nadkarni, Pooja Prabhakar Singh, Aditi Akshay Nadkarni, Prabhakar Mahendra Singh}

Nadkarni Group of Hospitals and 21st Century Fertility Clinics, Gujarat, India

Received: 02 December 2016

Accepted: 26 December 2016

\section{*Correspondence:}

Dr. Meeta Mohan Mahale,

E-mail: drmeeta198625@gmail.com

Copyright: () the author(s), publisher and licensee Medip Academy. This is an open-access article distributed under the terms of the Creative Commons Attribution Non-Commercial License, which permits unrestricted non-commercial use, distribution, and reproduction in any medium, provided the original work is properly cited.

\section{ABSTRACT}

Background: Hysteroscopy is a gold standard test for assessing the uterine cavity. The presence of uterine pathology may negatively affect the chance of implantation. This study investigated the use of routine office hysteroscopy and correction of any intrauterine pathologies prior to starting IVF cycle on treatment outcome in women seeking IVF treatment for primary infertility and recurrent implantation failure.

Methods: This was a retrospective study of 100 women who attended our infertility clinic from July 2016 to December 2016 and who were willing for office hysteroscopy. The main outcomes measured were clinical pregnancy rates achieved in the index IVF cycle, multiple pregnancy rate, ectopic pregnancy rate, miscarriage rate and failure rate.

Results: Of the 100 patients who participated in the study, 75 patients conceived, 25 patients failed to conceive. $80.64 \%$ patients with normal findings on diagnostic hysteroscopy conceived after the procedure, $58.33 \%$ patients conceived after polypectomy, $68.42 \%$ conceived after septal resection, $71.42 \%$ conceived after adhesiolysis, 50\% conceived after lateral metroplasty and $73.07 \%$ of recurrent implantation failure conceived after local endometrial injury was done on hysteroscopy.

Conclusions: Hysteroscopy in infertile women prior to their IVF cycle when performed atleast 3 months in advance could improve treatment outcome.

Keywords: Hysteroscopy, ICSI, Pregnancy rate

\section{INTRODUCTION}

IVF is an expensive treatment but results in a successful outcome in only a third of treatment cycles. ${ }^{1}$ Recurrent IVF implantation failure 2 or more failed IVF cycles is a very distressing experience to patients and increases the financial burden on the couple or the service provider. ${ }^{2}$ Office hysteroscopy is a well tolerated minimally invasive procedure which allows reliable visual assessment of the cervical canal and uterine cavity and provides the opportunity to perform therapy in the same setting. ${ }^{3,4}$ Currently there is evidence that performing hysteroscopy before starting IVF treatment could increase the chance of pregnancy in the subsequent IVF cycle in women who has 1 or more failed IVF cycles. ${ }^{5,6}$ This study aimed to analyse the outcome of office hysteroscopy performed prior to start of IVF cycle in a group of 100 patients in an IVF centre in Surat, Gujarat. Evaluate the outcome of office hysteroscopy on IVF cycle-whether performing office hysteroscopy prior to starting an IVF cycle improves likelihood of achieving a clinical pregnancy in infertile women.

\section{METHODS}

Design

A retrospective study of 100 women who attended Nadkarni $21^{\text {st }}$ century hospital and test tube baby centre, 
Surat over a period of 6 months-July 2016 to December 2016.

\section{Outcome}

Primary outcome - clinical pregnancy rate (beyond 28 weeks gestation)

Secondary outcome - multiple pregnancy rates, ectopic pregnancy rate, miscarriage rate, failure rate of cycle.

\section{Inclusion criteria}

Women undergoing an art treatment cycle with ICSI who may or may not have had previous IUI/ICSI cycles and willing for hysteroscopy were included. Written valid informed consent was taken prior to patients to the procedure.

\section{Exclusion criteria}

Women above age of 40 years were not included as the primary factor for failure in this age group is related to embryo quality which is unlikely to be corrected by uterine or endometrial anomaly correction.

\section{Procedure followed}

Per vaginal prostaglandin tablet of $200 \mathrm{mcg}$ was used as cervical softening agent prior to hysteroscopy, kept 1 hour prior to procedure. A rigid hysteroscope was put into the uterine cavity under visual control after minimal cervical dilatation only if absolutely required, normal saline was used as the distension medium, keeping the uterine pressure between 100 and $150 \mathrm{~mm}$ of mercury. Intrauterine lesions, such as, synechiae, polyps, submucosal myomas, septae, and so on, were treated with scissors and Versapoint. Every hysteroscopy was followed by endometrial biopsy or curettage, and the material obtained was sent for histopathological examination. Cases of RIF were treated with local endometrial injury with either curette or Versapoint.

\section{RESULTS}

Of the 100 patients who participated in the study, 75 patients conceived, 25 patients failed to conceive.

Table 1: Age distribution.

\begin{tabular}{|l|l|}
\hline Age group & No. of patients \\
\hline $20-25$ & 10 \\
\hline $26-30$ & 37 \\
\hline $31-35$ & 29 \\
\hline $36-40$ & 24 \\
\hline
\end{tabular}

$80.64 \%$ patients with normal findings on diagnostic hysteroscopy conceived after the procedure, $58.33 \%$ patients conceived after polypectomy, $68.42 \%$ conceived after septal resection, $71.42 \%$ conceived after adhesiolysis, $50 \%$ conceived after lateral metroplasty and $73.07 \%$ of recurrent implantation failure conceived after local endometrial injury was done on hysteroscopy.

Table 2: Patient profile.

\begin{tabular}{|llll|}
\hline $\begin{array}{l}\text { No. of } \\
\text { previous } \\
\text { ICSI }\end{array}$ & $\begin{array}{l}\text { No. of } \\
\text { patients }\end{array}$ & Conceived & Failed \\
\hline 0 & 63 & 50 & 13 \\
\hline 1 & 29 & 19 & 10 \\
\hline 2 & 6 & 5 & 1 \\
\hline$>2$ & 2 & 1 & 1 \\
\hline
\end{tabular}

Table 3: Distribution according to duration of infertility.

\begin{tabular}{|l|c|}
\hline No. of years of marital life & No. of patients \\
\hline $0-5$ & 33 \\
\hline $6-10$ & 42 \\
\hline $11-14$ & 10 \\
\hline$>15$ & 15 \\
\hline
\end{tabular}

\section{DISCUSSION}

The uterine cavity is considered to play an important role in successful implantation. Faghali et al., have also recommended screening the uterus by hysteroscopy before proceeding with IVF, to minimize implantation failures. ${ }^{7}$ The availability of hysteroscopes with smaller diameter has made the use of outpatient or office hysteroscopy feasible as a routine examination. ${ }^{8}$

The prevalence of unsuspected intrauterine abnormalities, diagnosed by hysteroscopy prior to IVF, has been reported to be $11-45 \% .^{9,10}$ Easier embryo transfer, more accurate embryo placement and enhanced endometrial receptivity secondary to endometrial stimulation have been considered as plausible explanations for the improved IVF outcome after normal hysteroscopy. ${ }^{11}$ Evidence exists that performing hysteroscopy before IVF treatment significantly increases the chance of pregnancy in the subsequent IVF cycle in women who had one or more failed IVF cycles. ${ }^{5}$ Karayalcin et al reported on a total of 2500 consecutive office-based diagnostic hysteroscopies in an IVF population enrolled prospectively prior to treatment. Endometrial pathology on hysteroscopy which may have impaired the success of IVF was identified in $22.9 \% .^{12}$

Karayalcin et al enrolled 1258 patients attending an IVF clinic with normal hysteroscopic findings in an attempt to establish the impact of timing of office hysteroscopy before embryo transfer on pregnancy rate. The implantation, pregnancy, and clinical pregnancy rates were significant when office hysteroscopy was performed 50 days or less before embryo transfer. ${ }^{13}$ 
Another recent study included 157 women with a history of recurrent IVF failures (two or more) who underwent hysteroscopy (diagnostic or operative, as appropriate) to evaluate the endometrial cavity. Abnormal hysteroscopic findings were found in $44.9 \%$ of the patients in this study and 75 women $(48.1 \%)$ became pregnant following hysteroscopy. Of these pregnancies, 36 occurred in women with corrected endometrial pathology, the majority of which was identified as endometrial polyps. ${ }^{14}$

Table 4: Hysteroscopic findings and outcome.

\begin{tabular}{|lllll|}
\hline $\begin{array}{l}\text { Hysteroscopic } \\
\text { finding }\end{array}$ & $\begin{array}{l}\text { Procedure } \\
\text { done }\end{array}$ & $\begin{array}{l}\text { No.of } \\
\text { cases }\end{array}$ & $\begin{array}{l}\text { No.of pregnancies post } \\
\text { procedure }\end{array}$ & $\begin{array}{l}\text { \% of conception post } \\
\text { procedure }\end{array}$ \\
\hline Normal & Diagnostic & 62 & 50 & $80.64 \%$ \\
\hline Polyp & Polypectomy & 12 & 7 & $58.33 \%$ \\
\hline Septa & Septal resection & 19 & 13 & $68.42 \%$ \\
\hline Blocked ostia & Direct ICSI & 48 & 35 & $72.91 \%$ \\
\hline Synechiae & Synechiolysis & 07 & 05 & $71.42 \%$ \\
\hline $\begin{array}{l}\text { Unicornuate uterus/T } \\
\text { shaped uterus }\end{array}$ & Lateral metroplasty & 02 & 01 & $50 \%$ \\
\hline $\begin{array}{l}\text { Endometrial scratching/LEI } \\
\text { done in patients with } \\
\text { previous ICSI failure }\end{array}$ & & 26 & 19 & $73.07 \%$ \\
\hline
\end{tabular}

Table 5: Pregnancy outcome.

\begin{tabular}{|c|c|}
\hline Total pt who conceived & 75 \\
\hline Single & 46 \\
\hline Twins & 21 \\
\hline Triplets & 4 \\
\hline IUFD & 1 \\
\hline Ectopic & 1 \\
\hline Missed abortion & 2 \\
\hline
\end{tabular}

The benefit of hysteroscopic surgery was further corroborated in a retrospective matched control study by Tomazevic et al. These authors evaluated the influence of septate, subseptate, and arcuate uterus on pregnancy and live birth rates in 2481 in conventionally stimulated IVF/intracytoplasmic sperm injection (ICSI) cycles.

Pregnancy rates after embryo transfer before hysteroscopic surgery were significantly lower, both in women with subseptate and septate uterus and in women with arcuate uterus compared with controls. When live birth rates were considered, differences were more evident. The differences disappeared upon hysteroscopic resection. ${ }^{15}$ The TROPHY trial aimed to assess whether hysteroscopy improves the livebirth rate following IVF treatment in women with recurrent failure of implantation. It concluded that outpatient hysteroscopy before IVF in women with a normal ultrasound of the uterine cavity and a history of unsuccessful IVF treatment cycles does not improve the livebirth rate. Further research into the effectiveness of surgical correction of specific uterine cavity abnormalities before IVF was warranted. ${ }^{16}$ Another latest study in Italy by Di Spiezio Sardo et al concluded that robust and high-quality RCTs are still needed before hysteroscopy can be regarded as a first-line procedure in all infertile women, especially during the basal clinical assessment of the couple. ${ }^{17}$ This study showed improvement in clinical pregnancy rate after hysteroscopy was done in patients prior to ICSI cycle,especially in cases of recurrent implantation failure.

\section{CONCLUSION}

The position of hysteroscopy in the management of the infertile female remains under debate. Although a variety of studies demonstrate that the procedure is well tolerated and effective in the treatment of intrauterine pathologies, there is no consensus on the effectiveness of hysteroscopic surgery in improving the prognosis of subfertile women. There are not enough prospective randomized trials to clearly demonstrate that surgical removal of all intrauterine abnormalities improves fertility or IVF outcomes. However, published observational results suggest a benefit for resection of submucosal leiomyomas, adhesions, and at least a subset of polyps in increasing pregnancy rates. So in a country like India with limited resources, definitely hysteroscopy should be utilized as a tool to diagnose uterine anomalies prior to ICSI cycles, correct them in the same sitting and then attempt ICSI cycle so as to improve implantation rate and clinical pregnancy rate.

Funding: No funding sources

Conflict of interest: None declared

Ethical approval: Not required

\section{REFERENCES}

1. Bouwmans CA, Lintsen BM, Eijkemans MJ, Habbema JD, Braat DD, Hakkaart L. A detailed cost analysis of in vitro fertilization and intracytoplasmic 
sperm injection treatment. Fertil Steril. 2008;89(2):331-41.

2. Verhaak C, Smeenk J, Evers A, Kremer J, Kraaimaat F, Braat D:Women's emotional adjustment to IVF: a systematic review of 25 years of research. Human Reproductive Update. 2007;13:27-36.

3. Urman B, Yakin K, Balaban B: Recurrent implantation failure in assisted reproduction: how to counsel and manage. A. General considerations and treatment options that may benefit the couple. Reproductive BioMedicine Online. 2005;11:371-81.

4. Kirsop R, Porter R, Torode H, Smith D, Saunders D. The role of hysteroscopy in patients having failed IVF/GIFT transfer cycles. Australian and New Zealand Journal of Obstetrics and Gynaecology. 1991;31:263-4.

5. Bosteels J, Weyers S. The effectiveness of hysteroscopy in improving pregnancy rates in subfertile women without other gynaecological symptoms: a systematic review. Hum Reprod Update. 2010;16:1-11.

6. El Toukhy T, Sunkara SK, Coomarasamy A, Grace J, Khalaf Y. Outpatient hysteroscopy and subsequent IVF cycle outcome: A systematic review and meta analysis. Reprod Biomed Online. 2008;16:712-9.

7. Faghali J, Bakar J, Mayenga JM, Ségard L, Hamou J, Driguez P, et al. Systematic hysteroscopy prior to In vitro fertilisation. Gynecol Obstet Fertil. 2003;31:127-3.

8. De Placido, G., Clarizia, R., Cadente, C., Castaldo, G., Romano, C.,Mollo,et al. Compliance and diagnostic efficacy of mini-hysteroscopy versus traditional hysteroscopy in infertility investigation. Eur J Obstet Gynecol Reprod Biol. 2007;135:83-7.

9. El-Mazny A, Abou-Salem N, El-Sherbiny W, Saber $\mathrm{W}$ : Outpatient hysteroscopy: a routine investigation before assisted reproductive techniques? Fertil Steril. 2011;95(1):272-6.

10. 10.Makrakis E, Pantos K: The outcomes of hysteroscopy in women with implantation failures after in-vitro fertilization: findings and effect on subsequent pregnancy rates. Curr Opin Obstet Gynecol. 2010;22(4):339-43.

11. Dhulkotia J, Coughlan C. Effect of endometrial injury on subsequent pregnancy rates in women undergoing IVF after previous implantation failure: systematic review and meta-analysis. BJOG. 2012;119:132-3.

12. Karayalcin R, Ozcan S. Results of 2500 office-based diagnostic hysteroscopies before IVF. Reproductive BioMedicine Online. 2010;20(5):689-93.

13. Karayalcin R, Ozcan S. Office hysteroscopy improves pregnancy rates following IVF. Reproductive BioMedicine Online. 2012;25(3):2616.

14. Cenksoy P, Ficicioglu C, Yildirim G, Yesiladali M. Hysteroscopic findings in women with recurrent IVF failures and the effect of correction of hysteroscopic findings on subsequent pregnancy rates. Arch Gynecol Obstet. 2013;287:357-60.

15. Tomazevic T, Ban-Frangez H. Septate, subseptate and arcuate uterus decrease pregnancy and live birth rates in IVF/ICSI. Reproductive Bio Medicine Online. 2010;21(5):700-5.

16. El-Toukhy T, Campo R. Hysteroscopy in recurrent in-vitro fertilisation failure (TROPHY): a multicentre, randomised controlled trial. The Lancet Choice. 2016;387:2614-21.

17. Spiezio Sardo AD, Di Carlo C. Efficacy of hysteroscopy in improving reproductive outcomes of infertile couples: a systematic review and metaanalysis. Hum Reprod Update. 2016;22(4):479-96.

Cite this article as: Mahale MM, Nadkarni PK, Nadkarni KM, Singh PP, Nadkarni AA, Singh PM. Office Hysteroscopy prior to ART cycle-analysis and outcome at a private IVF clinic setup in Surat, Gujarat, India. Int $\mathbf{J}$ Reprod Contracept Obstet Gynecol 2017;6:611-4. 